\title{
Seed Priming and Tolerance to Salt and Water Stress in Divergent Grain Sorghum Genotypes
}

\author{
Charles Lobo Pinheiro*, Hellen Thayse Nascimento Araújo, Selma Freire de Brito, \\ Marcos da Silva Maia, Jesimiel da Silva Viana, Sebastião Medeiros Filho \\ Department of Plant Science, Federal University of Ceará, Fortaleza, Brazil \\ Email: ${ }^{\star}$ charlesclp@yahoo.com.br
}

How to cite this paper: Pinheiro, C.L., Araújo, H.T.N., de Brito, S.F., Maia, M. da S., Viana, J. da S. and Filho, S.M. (2018) Seed Priming and Tolerance to Salt and Water Stress in Divergent Grain Sorghum Genotypes. American Journal of Plant Sciences, 9, 606-616.

https://doi.org/10.4236/ajps.2018.94047

Received: January 23, 2018

Accepted: March 6, 2018

Published: March 9, 2018

Copyright $\odot 2018$ by authors and Scientific Research Publishing Inc. This work is licensed under the Creative Commons Attribution International License (CC BY 4.0).

http://creativecommons.org/licenses/by/4.0/

\begin{abstract}
Tolerance to water and salt stress during germination and growth of agricultural species might have superior results when seeds are submitted to priming processes. The objective of the present study was to evaluate the use of hydropriming and hormonal priming with gibberellic acid $\left(\mathrm{GA}_{3}\right)$ on the tolerance of divergent genotypes of sorghum to salt and water stress during germination and seedling growth. The genotypes analyzed were cultivar BRS 330 and lineage 201420, which are the most and least tolerant to water and salt stress, respectively. Sowing was undertaken under control (no stress), water stress $(-0.6 \mathrm{MPa})$, and salt stress $\left(20 \mathrm{dS} \cdot \mathrm{m}^{-1}\right)$ conditions, and the seeds were subjected to the following treatments: control-no immersion; hydropriming-immersion for 2 hours in distilled water; and hormonal priming-immersion in $\mathrm{GA}_{3}$ solutions, at concentrations of 50,75, and $100 \mathrm{ppm}$, for 2 hours. After soaking, the seeds were dried for 24 hours at a temperature of $30^{\circ} \mathrm{C} \pm 2{ }^{\circ} \mathrm{C}$. The variables analyzed were percentage and germination speed index, root and shoot lengths, and root/shoot ratio. The stress conditions analyzed negatively affected the two genotypes; however, the seeds that underwent priming processes improved the performance of the genotypes under salt and water stress conditions, especially when using seeds of the more tolerant genotype (BRS 330) subjected to hormonal priming at $100 \mathrm{ppm} \mathrm{GA}_{3}$ concentration.
\end{abstract}

\section{Keywords}

Hydropriming, Hormonal Priming, Gibberellic Acid, Sorghum bicolor

\section{Introduction}

Sorghum [Sorghum bicolor (L.) Moench] is prominent worldwide as being one of the most produced cereals, and is known for being easy to cultivate [1]. 
Moreover, it is very versatile and is included in the production of human and animal food, as well as alcohol and industrial products [2].

Cultivation of this crop is centered in tropical and subtropical regions, primarily in marginal areas that are more stress-prone [3]. These conditions of stress, especially abiotic ones, are the biggest causes of the reduction of sorghum yield [4], although these are minimized owing to its greater tolerance to stress compared to other cereals [5].

The effects of environmental restrictions on plants have received increasing attention due to the potential impacts of climate change [6], which might hinder the maintenance of, and increase in, agricultural productivity, especially in arid and semi-arid regions [7]. In particular, this is due to agricultural losses related to increases in salinity and drought, which are some of the main abiotic limiting factors in these regions [6]. These conditions might cause stress that influences the entire plant, causing damage to all major plant processes, including germination, photosynthesis, water and nutrient absorption, or even causing death of the plant [8].

Germination and growth of seedlings are considered to be the most vulnerable stages to damage caused by drought and excess salts [9]; therefore, the capacity of plants to overcome these more sensitive stages is decisive for survival and establishment [10]. However, the adoption of strategies such as the use of more tolerant genotypes, application of growth regulators, use of osmoprotectants, and the induction of tolerance via denominated priming techniques have been employed to overcome or minimize the damage caused by these abiotic factors during these stages [11].

Priming is a technique that is considered fast and inexpensive, and can be employed to overcome the effects of abiotic stresses [8] [12], in which exposure to moderate stress induces greater tolerance for subsequent stress events [13]. This technique can be applied to various agricultural species and can be applied to seeds or plants [8].

The application of this technique in seeds consists of partial hydration, without radicle protrusion, followed by drying [8] [12] [14]. The hydration process is performed using different techniques, e.g., immersion of seeds in water (hydropriming), osmotic solution (osmotic priming), chemicals (chemical priming), or hormones (hormonal priming) [14].

In a study conducted by [15] on a crop of sorghum, the hormonal priming of gibberellic acid $\left(\mathrm{GA}_{3}\right)$ or salicylic acid was proven to reduce the negative effects of water stress during the initial phase of culture. However, there is no information as to whether these treatments could improve tolerance to other stress conditions such as that caused by salinity/salt and if the tolerance variation in genotypes influences the choice of treatment.

Therefore, the present study aimed to evaluate the use of hydropriming and hormonal priming with $\mathrm{GA}_{3}$ on the tolerance of divergent genotypes of sorghum to determine the effects of water and salt stresses during the germination and 
growth in seedlings.

\section{Material and Methods}

The research was conducted in the Seed Analysis Laboratory at the Federal University of Ceará. The seeds analyzed were from cultivar BRS 330 and lineage 201420 (L-20), originating from the seed bank of the agriculture department of the state of Ceará and of Research Center for Corn and Sorghum of Brazilian Company of Agricultural Research (EMBRAPA), respectively. At preliminary performance analyzes under different salt concentrations and osmotic potentials showed that at concentrations of $20 \mathrm{dS} \cdot \mathrm{m}^{-1}$ and $-0.6 \mathrm{MPa}$, respectively, these genotypes presented contrasting behavior, i.e., BRS 330 was more tolerant than L-20 to these stresses during the initial phase of the culture.

The seeds were all disinfected by immersing them in $2 \%$ sodium hypochlorite for 5 minutes and then washing under running water for 2 minutes. Afterwards, the seeds were placed on paper towels to remove excess water. After drying, the seeds of each genotype were submitted to the partial hydration process for 2 hours in B.O.D., with a temperature of $25^{\circ} \mathrm{C}$ and lights-off. The hydration of the seeds was performed via immersion, in the treatments presented in Table 1 , and afterward was distributed between sheets of paper towel, and dried for 24 hours at a temperature of $30^{\circ} \mathrm{C}$.

The treated seeds were seeded on Germitest ${ }^{\oplus}$ paper under three conditions: non-stress-substrate moistened with distilled water; water stress-substrate moistened with osmotic solution, adjusted to $-0.6 \mathrm{MPa}$, obtained by dilution of polyethylene glycol 6000 (PEG) in distilled water based on the protocol described by [16]; and salt stress-salt solution applied at a concentration of $20 \mathrm{dS} \cdot \mathrm{m}^{-1}$, adjusted by the dilution of sodium chloride $(\mathrm{NaCl})$ in distilled water based on the equation of [17].

Thus, each genotype was submitted to 15 treatments, formed by the factorial arrangement of the 5 treatments applied to the seeds (control, hydropriming, and hormonal priming with 50,75 , and $100 \mathrm{ppm} \mathrm{GA}_{3}$ ), combined with the 3 sowing conditions (non-stress, waterstress, and salt stress). Each treatment consisted of 200 seeds, subdivided into 4 replicates of 50 seeds, distributed onto sheets of Germitest ${ }^{\oplus}$ paper and packed into transparent plastic bags to reduce the loss of water. The sheets were arranged randomly and vertically within a B.O.D. chamber, remaining conditioned for 10 days, with temperature set at $25^{\circ} \mathrm{C} \pm 2^{\circ} \mathrm{C}$

Table 1. Treatments applied to the seeds of the grain sorghum genotypes.

\begin{tabular}{cc}
\hline Treatments & Description \\
\hline Control & No immersion; \\
Hydropriming & Immersion in distilled water; \\
$50 \mathrm{ppm} \mathrm{de} \mathrm{GA}$ & Immersion in $\mathrm{GA}_{3}$ solution, at concentration of $50 \mathrm{ppm} ;$ \\
$75 \mathrm{ppm} \mathrm{de} \mathrm{GA}_{3}$ & Immersion in $\mathrm{GA}_{3}$ solution, at concentration of $75 \mathrm{ppm} ;$ \\
$100 \mathrm{ppm} \mathrm{de} \mathrm{GA}_{3}$ & Immersion in $\mathrm{GA}_{3}$ solution, at concentration of $100 \mathrm{ppm}$. \\
\hline
\end{tabular}


and photoperiod of 12 hours light [18].

The effects of the treatments were evaluated using the following variables: percentage of germination, which was determined on the tenth day of incubation by counting the number of germinated seeds, based on the number of seeds that generated normal seedlings [18]; germination speed index (GSI), which was calculated by counting the number of seeds germinated daily using the Maguire's equation [19], on what: GSI = Number of normal seedlings/Days to first count $+\cdots+$ Number of normal seedlings/Days to final count; root and shoot lengths, which were determined with a ruler graduated in millimeters, with a final result obtained by averaging the measurements of 15 seedlings taken randomly from each replicate after 10 days of incubation; and root/shoot ratio.

Analyzes of the effect of the treatments in the two divergent genotypes were performed separately. The results of the analyzed variables were submitted to analysis of variation (ANOVA) and when they presented a significant difference they were submitted to the Tukey test, at a level of $5 \%$ of significance, to compare the means. The data were analyzed using SISVAR ${ }^{\circledR}$ software version 5.6 and SigmaPlot ${ }^{\circledast}$ software version 11.0 was used for graphical representation of the results.

\section{Results and Discussion}

The germination of the genotypes BRS 330 and L-20 presented variations related to the interaction of the sowing conditions and the type of treatment applied to the seeds $(\mathrm{p}<0.01)$. The highest germination percentages of the two genotypes were obtained under non-stress conditions, in which the genotypes BRS 330 and L-20 presented $84.3 \%$ and $80.8 \%$ germination, respectively. There was no significant difference between the treatments applied to the sowing seeds under non-stress conditions $(\mathrm{p}>0.05)$ (Figure 1).

Control

$\square$ Hydropriming

BRS 330

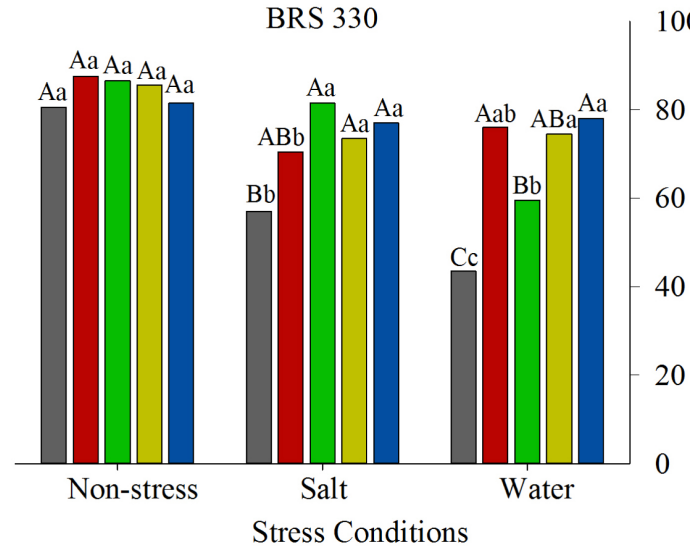

$\square 75 \mathrm{ppm} \mathrm{GA}_{3} \square 100 \mathrm{ppm} \mathrm{GA}_{3}$ L-20
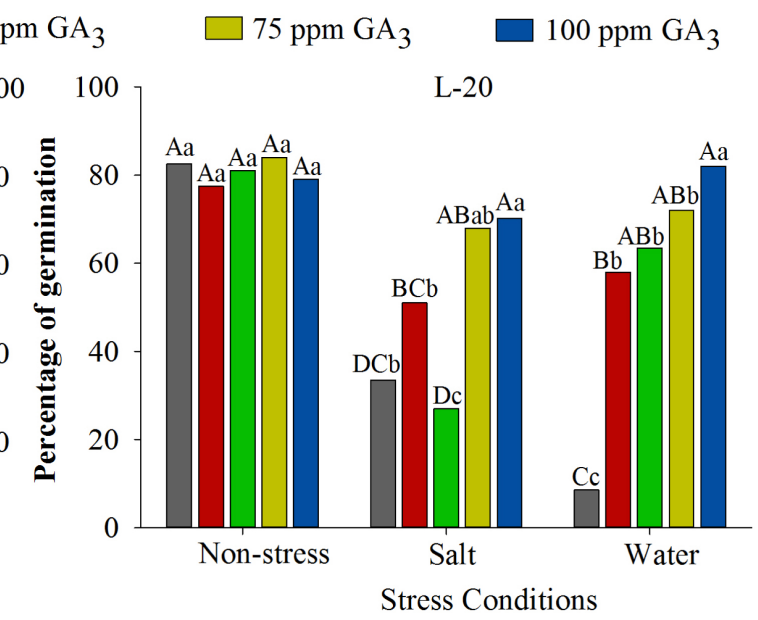

Figure 1. Percentage of germination of sorghum genotypes submitted to different priming treatments and sowed under non-stress and salt and water stress. Means followed by the same capital letter, under the stress condition, and by the same small letter, between the stress conditions, did not differ among themselves when compared by the Tukey test at $5 \%$ of probability. 
However, salt and water stress conditions were found to be harmful to germination, especially for seeds that did not receive any treatment (control) in the two genotypes $(\mathrm{p}<0.05)$. Under the salt stress $\left(20 \mathrm{dS} \cdot \mathrm{m}^{-1}\right)$ and water stress $(-0.6$ $\mathrm{MPa}$ ) conditions, the L-20 genotype showed $33.5 \%$ and $8.5 \%$ germination, respectively, whereas the BRS 330 genotype germination at these stress levels were $57 \%$ and $43.5 \%$, respectively. This difference is explained by the genetic difference between the genotypes. However, the use of priming seeds treated with hormones at a concentration of $100 \mathrm{ppm} \mathrm{GA}_{3}$ provided stability for the genotypes germination, with no significant difference between the germination of seeding conditions analyzed ( $\mathrm{p}>0.05)$.

These results corroborate with [15] who, after evaluating the germination of sorghum sown under a water stress condition, verified that hormonal priming with $\mathrm{GA}_{3}$ or salicylic acid at $50 \mathrm{ppm}$ for 24 hours promoted a $15 \%$ to $20 \%$ increase in germination compared to untreated seeds. In the present study, the seeds of both sorghum genotypes treated with 50 ppm $\mathrm{GA}_{3}$ for 2 hours also had increased germination under water stress from $35 \%$ to $40 \%$ (Figure 1). Yet, in the salt stress condition, a significant increase was verified only for genotype BRS 330. This result is probably related to differences in tolerance to salt stress of genotypes, indicating that seeds of more tolerant genotypes are easier to have their tolerance improved, allowing the use of lower concentrations of hormonal substances applied via priming. However, the concentration of $50 \mathrm{ppm} \mathrm{GA}$ did not allow stability of germination as verified in the $100 \mathrm{ppm}$ concentration. In addition, the seeds of the L-20 (less tolerant) genotype, submitted to priming with 100 ppm $\mathrm{GA}_{3}$, showed a 65\% increase in germination in the controls under water stress conditions of $-0.6 \mathrm{MPa}$.

The increase of sorghum germination in sub-optimal moisture conditions has also been achieved by applying osmotic priming based on PEG 8000 for 48 hours in an environment with controlled temperature of $18^{\circ} \mathrm{C}$, followed by slow drying at $20^{\circ} \mathrm{C}$ until the seed reached the initiated water content [20]. The treatment of grain sorghum seeds by priming with 100 ppm $\mathrm{GA}_{3}$ has been shown to be a more practical and quicker way of guaranteeing the stability of germination of distinct genotypes under conditions of water and salt stress.

Under conditions of abiotic stresses, as verified for sorghum, different priming processes can be used to maintain germination, which was demonstrated by [21] who verified that hydropriming, hormonal priming (with $\mathrm{GA}_{3}$ and Cyco$\mathrm{cel}^{\circledR}$ ), and salt (with $\mathrm{KNO}_{3}$, and $\mathrm{KCl}$ ) provided the highest germination of different varieties of wheat (Triticum aestivum L.) grown in sodium soil. Therefore, the priming technique that provides the highest germination under conditions of abiotic stress represents an important tool in the selection of the most viable, accessible, practical, and efficient method for each crop. However, few studies have proven the efficiency in divergent genotypes regarding tolerance to these stresses.

Hormonal priming with $100 \mathrm{ppm} \mathrm{GA}_{3}$ also provided an increase in the rate of germination speed of both genotypes under conditions of salt and water stress 
(Figure 2). However, there was no influence of the treatments in the non-stress condition, which presented the highest averages.

Faster germination under salt and water stress of seeds treated with priming might be related to higher metabolic activity of the seeds before germination. Based on a study by [14], this is one of the mechanisms activated by the priming techniques to improve the germination process. In cereals, it might be related to enzymatic activation of $\alpha$-amylase, which is responsible for starch hydrolysis and embryo nutrition [21], and $\mathrm{GA}_{3}$ is responsible for the activation of this enzyme [22].

Based on results of a study by [23], priming with $\mathrm{GA}_{3}$ or $\mathrm{NaCl}$ promotes the activation of several metabolic processes linked to germination, even in low potential conditions, which accelerates the germination process. [24] demonstrated this for millet culture [Pennisetum glaucum (L.) R. Br] that had seeds submitted to osmotic priming (PEG) and hormonal priming (salicylic acid). Therefore, different types of priming might contribute to the germination process faster under stress conditions, as well as $\mathrm{GA}_{3}$ hormonal priming for sorghum.

Regarding the effect of priming on growth, it was verified that the treatment with $75 \mathrm{ppm} \mathrm{GA}_{3}$ provided superior growth of the aerial part of the different genotypes under conditions of water and salt stress compared to the control, whereas the other priming presented variations between the types of stress and genotypes. However, shoot growth under stress conditions was lower than under non-stress conditions. In the non-stress condition, we observed a variation between the priming, where hydropriming reduced the shoot growth of BRS 330 and hormonal priming at 75 and $100 \mathrm{ppm} \mathrm{GA}_{3}$ for L-20 decreased approximately $2 \mathrm{~cm}$ in growth of the aerial part of this genotype compared to the control (Figure 3).

According to [12] and [25], priming based on phytohormones such as $\mathrm{GA}_{3}$,

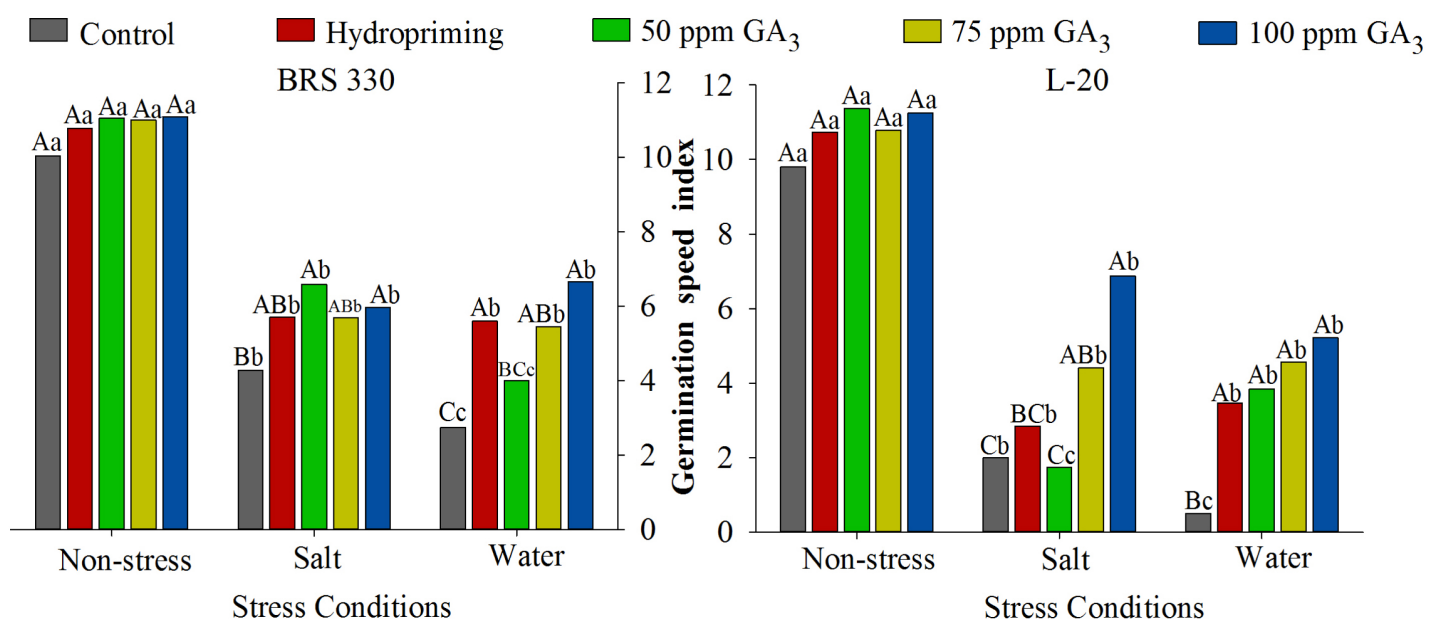

Figure 2. Germination speed index of sorghum genotypes submitted to different priming treatments and sowed under non-stress, salt and water stress. Means followed by the same capital letter, under the stress condition, and by the same small letter, between the stress conditions, did not differ among themselves when compared by the Tukey test at $5 \%$ of probability. 
Control

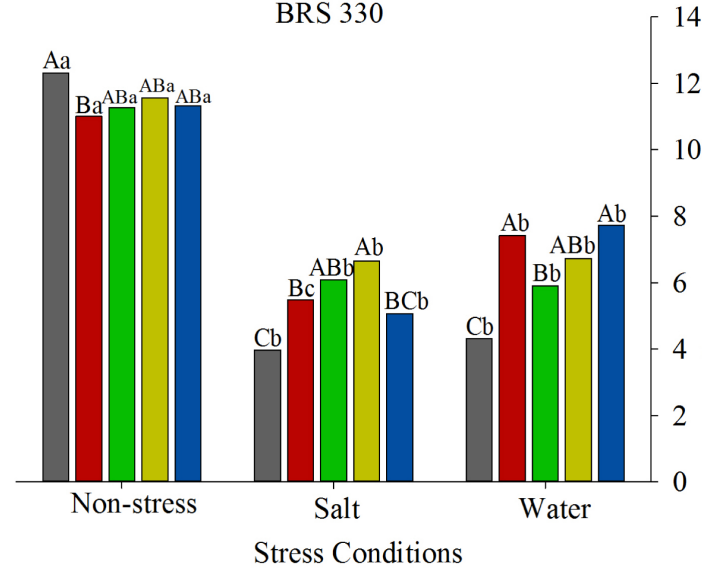

L-20

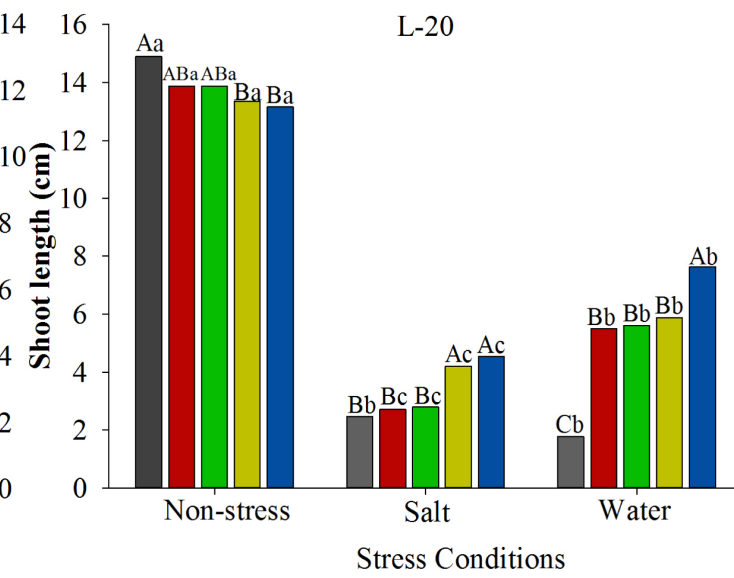

Figure 3. Shoot length of seedlings of sorghum genotypes, submitted to different priming treatments and sowed under non-stress, salt and water stress. Means followed by the same capital letter, under the stress condition, and by the same small letter, between the stress conditions, did not differ among themselves when compared by the Tukey test at $5 \%$ of probability.

cytokinin, auxin, jasmonic acid, and salicylic acid might contribute to the growth and development of seedlings in stressful or stress-free environments [12] [25]. However, according to [26] the priming effect may vary depending on the type of solution and concentration. In the grain sorghum culture in the present study it was verified that variations can also be influenced by the difference between the types of stress and the tolerance of the genotypes (Figure 3).

Regarding root growth, the analyzed factors presented interaction only in genotype BRS $330(\mathrm{p}<0.01)$, whereas for L-20 a difference was only found between the means of the isolated factors. The different priming techniques promoted the growth of the radicles of the L-20 genotype, with the condition of non-stress being the most favorable and the condition of salt stress being the most limiting (Table 2). However, for the root growth of the BRS 330 genotype under the water stress condition, only the seeds treated with 100 ppm $\mathrm{GA}_{3}$ presented growth superior to the control, and in all other conditions all priming promoted the highest growth.

According to [27], higher root growth in seedlings under conditions of water or salt stress is an adaptation to increase the covered catchment area and improve productivity. In view of this, can be affirmed that the priming of seeds of sorghum with $100 \mathrm{ppm} \mathrm{GA}_{3}$ improves the uptake of water in an environment with or without stress.

Hormonal priming with $\mathrm{GA}_{3}$ and salicylic acid increased the root growth of wheat under salt stress [28], and priming with $\mathrm{KNO}_{3}$ and urea also promoted the highest growth in the radicle of maize hybrids, maximum, sc704, and sc304, under different levels of water and salt stress. [20] and [29] affirmed that higher growth of seedlings was due to the effect of the different types of priming increasing the activity of the antioxidant enzymes, which alleviate the damage of 
Table 2. Root length of the seedlings of sorghum genotypes submitted to the different treatments with priming and sowed in the conditions of non-stress, salt and water stress.

\begin{tabular}{|c|c|c|c|c|c|c|}
\hline TREATMENTS & \multicolumn{3}{|c|}{ BRS 330} & \multicolumn{3}{|c|}{ L-20 } \\
\hline \multicolumn{7}{|l|}{ Stress conditions } \\
\hline Non-stress & \multicolumn{3}{|c|}{$15.97 \mathrm{~A}$} & \multicolumn{3}{|c|}{$18.22 \mathrm{~A}$} \\
\hline Salt & \multicolumn{3}{|c|}{$9.32 \mathrm{~B}$} & \multicolumn{3}{|c|}{$9.80 \mathrm{C}$} \\
\hline Water & \multicolumn{3}{|c|}{$13.58 \mathrm{C}$} & \multicolumn{3}{|c|}{$15.83 \mathrm{~B}$} \\
\hline LDS & \multicolumn{3}{|c|}{$1.05(\mathrm{p}<0.05)$} & \multicolumn{3}{|c|}{$1.60(\mathrm{p}<0.05)$} \\
\hline \multicolumn{7}{|l|}{ Seed treatments } \\
\hline Control & \multicolumn{3}{|c|}{$11.03 \mathrm{~A}$} & \multicolumn{3}{|c|}{$10.36 \mathrm{~B}$} \\
\hline Hydropriming & \multicolumn{3}{|c|}{$13.24 \mathrm{~A}$} & \multicolumn{3}{|c|}{$15.12 \mathrm{~A}$} \\
\hline $50 \mathrm{ppm} \mathrm{de} \mathrm{GA}_{3}$ & \multicolumn{3}{|c|}{$13.09 \mathrm{~A}$} & \multicolumn{3}{|c|}{$14.72 \mathrm{~A}$} \\
\hline $75 \mathrm{ppm} \mathrm{de} \mathrm{GA}_{3}$ & \multicolumn{3}{|c|}{$13.68 \mathrm{~A}$} & \multicolumn{3}{|c|}{$16.18 \mathrm{~A}$} \\
\hline 100 ppm de $\mathrm{GA}_{3}$ & \multicolumn{3}{|c|}{$13.75 \mathrm{~A}$} & \multicolumn{3}{|c|}{$16.73 \mathrm{~A}$} \\
\hline LDS & \multicolumn{3}{|c|}{$2.65(\mathrm{p}<0.05)$} & \multicolumn{3}{|c|}{$2.43(\mathrm{p}<0.05)$} \\
\hline \multirow[t]{2}{*}{ Interaction } & \multicolumn{3}{|c|}{ BRS 330} & \multicolumn{3}{|c|}{ L-20 } \\
\hline & Non-stress & Salt & Water & Non-stress & Salt & Water \\
\hline Control & $13.13 \mathrm{Ba}$ & $6.97 \mathrm{Bb}$ & $13.13 \mathrm{BCa}$ & 14.73 & 6.11 & 10.25 \\
\hline Hydropriming & $16.08 \mathrm{Aa}$ & $9.37 \mathrm{Ac}$ & $14.27 \mathrm{ABb}$ & 19.27 & 9.33 & 16.74 \\
\hline $50 \mathrm{ppm} \mathrm{de} \mathrm{GA}_{3}$ & $16.55 \mathrm{Aa}$ & $10.80 \mathrm{Ab}$ & $11.92 \mathrm{Cb}$ & 18.52 & 9.32 & 16.31 \\
\hline $75 \mathrm{ppm} \mathrm{de} \mathrm{GA}_{3}$ & $17.14 \mathrm{Aa}$ & $10.39 \mathrm{Ac}$ & 13.53 ABCb & 19.02 & 11.84 & 17.69 \\
\hline $100 \mathrm{ppm} \mathrm{de} \mathrm{GA}_{3}$ & $17.09 \mathrm{Aa}$ & $9.10 \mathrm{Ac}$ & $15.07 \mathrm{Ab}$ & 19.58 & 12.42 & 18.18 \\
\hline LDS & \multicolumn{3}{|c|}{$1.83(\mathrm{p}<0.05)^{*}$} & $\mathrm{~ns}(\mathrm{p}>0.05)$ & \multicolumn{2}{|c|}{$\mathrm{ns}(\mathrm{p}>0.05)$} \\
\hline
\end{tabular}

LDS-least significant difference; ${ }^{*}$ column LDS; ${ }^{*}$ line LDS; ns-no significant difference $(\mathrm{p}>0.05)$. Means followed by the same capital letter, in the column, and by the same small letter, in the line, did not differ between them when compared by the Tukey test at $5 \%$ of probability.

the stresses and, consequently, promote higher growth of the roots and aerial part of the plant.

Stress conditions also caused phenotypic changes in the ratio between root and shoot growth, but this variable in the L-20 genotype not influenced by priming in the present study (Table 3). However, under water and salt stress conditions, the seedlings invested more in root growth than in the aerial part growth in seedlings that grew in the non-stress condition. The BRS 330 genotype was influenced by the interaction of factors $(\mathrm{p}<0.01)$ and the treatment of seeds with $100 \mathrm{ppm} \mathrm{GA}_{3}$ was the only one that could promote the balance of the root/shoot ratio under different stress conditions.

Variation in the root to shoot ratio has been found to be highly correlated with stress conditions [30], with the greatest variation of this ratio related to stress sensitivity [31]. In addition, this amendment aims to ensure the supply of resources at appropriate levels to meet the needs of plants [22]. Therefore, the lower root and shoot growth ratio of the sorghum seedlings from seeds treated with priming compared to untreated under stress conditions might indicate a 
Table 3. Root/shoot ratio of seedlings of sorghum genotypes, submitted to different priming treatments and sowed in the conditions of non-stress and salt and water stress.

\begin{tabular}{|c|c|c|c|c|c|c|}
\hline TREATMENTS & \multicolumn{3}{|c|}{ BRS 330} & \multicolumn{3}{|c|}{$\mathrm{L}-20$} \\
\hline \multicolumn{7}{|l|}{ Stress conditions } \\
\hline Non-stress & \multicolumn{3}{|c|}{$1.39 \mathrm{~B}$} & \multicolumn{3}{|c|}{$1.33 \mathrm{~B}$} \\
\hline Salt & \multicolumn{3}{|c|}{$1.72 \mathrm{AB}$} & \multicolumn{3}{|c|}{$3.03 \mathrm{~A}$} \\
\hline Water & \multicolumn{3}{|c|}{$2.23 \mathrm{~A}$} & \multicolumn{3}{|c|}{$3.19 \mathrm{~A}$} \\
\hline LDS & \multicolumn{3}{|c|}{$0.70(\mathrm{p}<0.05)$} & \multicolumn{3}{|c|}{$1.06(\mathrm{p}<0.05)$} \\
\hline \multicolumn{7}{|l|}{ Seed treatments } \\
\hline Control & \multicolumn{3}{|c|}{1.98} & \multicolumn{3}{|c|}{2.72} \\
\hline Hydropriming & \multicolumn{3}{|c|}{1.72} & \multicolumn{3}{|c|}{2.64} \\
\hline $50 \mathrm{ppm} \mathrm{de} \mathrm{GA}_{3}$ & \multicolumn{3}{|c|}{1.76} & \multicolumn{3}{|c|}{2.57} \\
\hline $75 \mathrm{ppm} \mathrm{de} \mathrm{GA}_{3}$ & \multicolumn{3}{|c|}{1.69} & \multicolumn{3}{|c|}{2.43} \\
\hline $100 \mathrm{ppm}$ de $\mathrm{GA}_{3}$ & \multicolumn{3}{|c|}{1.76} & \multicolumn{3}{|c|}{2.21} \\
\hline LDS & \multicolumn{3}{|c|}{$\mathrm{ns}(\mathrm{p}>0.05)$} & \multicolumn{3}{|c|}{ ns $(\mathrm{p}>0.05)$} \\
\hline \multirow[t]{2}{*}{ Interaction } & \multicolumn{3}{|c|}{ BRS 330} & \multicolumn{3}{|c|}{$\mathrm{L}-20$} \\
\hline & Non-stress & Salt & Water & Non-stress & Salt & Water \\
\hline Control & $1.06 \mathrm{Ac}$ & $1.73 \mathrm{Ab}$ & $3.18 \mathrm{Aa}$ & 0.99 & 2.67 & 4.5 \\
\hline Hydropriming & $1.46 \mathrm{Ac}$ & 1.74 Aab & $1.95 \mathrm{Ba}$ & 1.39 & 3.46 & 3.08 \\
\hline $50 \mathrm{ppm} \mathrm{de} \mathrm{GA}_{3}$ & $1.47 \mathrm{Ab}$ & 1.78 Aab & $2.02 \mathrm{Ba}$ & 1.34 & 3.41 & 2.95 \\
\hline $75 \mathrm{ppm} \mathrm{de} \mathrm{GA}_{3}$ & $1.48 \mathrm{Ab}$ & $1.56 \mathrm{Ab}$ & $2.03 \mathrm{Ba}$ & 1.43 & 2.84 & 3.02 \\
\hline $100 \mathrm{ppm} \mathrm{de} \mathrm{GA}_{3}$ & $1.51 \mathrm{Aa}$ & $1.80 \mathrm{Aa}$ & $1.96 \mathrm{Ba}$ & 1.49 & 2.75 & 2.38 \\
\hline LDS & \multicolumn{3}{|c|}{$0.52(\mathrm{p}<0.05)^{\star}$} & $\mathrm{ns}(\mathrm{p}>0.05$ & \multicolumn{2}{|c|}{$\mathrm{ns}(\mathrm{p}>0.05)$} \\
\hline
\end{tabular}

LDS-least significant difference; ${ }^{*}$ column LDS; ${ }^{*}$ line LDS; ns-no significant difference $(\mathrm{p}>0.05)$. Means followed by the same capital letter, in the column, and by the same small letter, in the line, did not differ between them when compared by the Tukey test at $5 \%$ of probability.

greater adaptation to continue absorbing the necessary resources without significant variations in their standard growth. In addition, this higher modification of the ratio would then occur at higher levels of stress conditions, mainly for the BRS 330 genotype treated with 100 ppm $\mathrm{GA}_{3}$.

\section{Conclusion}

The efficiency of priming varies among genotypes where germination and seedling growth of the more tolerant genotype (BRS 330) responded better to treatments. The application of hormonal priming with $100 \mathrm{ppm} \mathrm{GA}_{3}$ promoted superior germination and vigor of seedlings of divergent grain sorghum genotypes sowed under conditions of water $(-0.6 \mathrm{MPa})$ and salt $\left(20 \mathrm{dS} \cdot \mathrm{m}^{-1}\right)$ stress.

\section{References}

[1] Queiroz, V.A.V., Moraes, E.A., Schaffert, R.E., Moreira, A.V., Ribeiro, S.M.R. and Martino, H.S.D. (2011) Potencial funcional e tecnologia de processamento do sorgo. Revista Brasileira de Milho e Sorgo, 10, 180-195. 
https://doi.org/10.18512/1980-6477/rbms.v10n3p180-195

[2] Awika, J.M. and Rooney, L.W. (2004) Sorghum Phytochemicals and Their Potential Impact on Human Health. Phytochemistry, 65, 1199-1221. https://doi.org/10.1016/j.phytochem.2004.04.001

[3] Reddy, P.S. and Patil, J.V. (2015) Genetic Enhancement of Rabi Sorghum. Nikki Levy, Chennai.

[4] Souza, A.P., Cocuron, J.C., Garcia, A.C., Alonso, A.P. and Buckeridge, M.S. (2015) Changes in Whole-Plant Metabolism during Grain-Filling Stage in Sorghum bicolor L. (Moench) Grown under Elevated $\mathrm{CO}_{2}$ and Drought. Plant Physiology, 169, 1755-1765.

[5] Mutisya, J., Sun, C., Rosenquist, S., Baguma, Y. and Jansson, C. (2009) Diurnal Oscillation of SBE Expression in Sorghum Endosperm. Journal of Plant Physiology, 166, 428-434. https://doi.org/10.1016/j.jplph.2008.06.017

[6] Oliveira, A.B., Alencar, N.L. and Gomes-Filho, E. (2013) Comparison between the Water and Salt Stress Effects on Plant Growth and Development. In: Akınc1, S., Ed., Responses of Organisms to Water Stress, INTECH Open Access Publisher, Croatia, 67-94. https://doi.org/10.5772/54223

[7] Fita, A., Rodríguez-Burruezo, A., Boscaiu, M., Prohens, J. and Vicente, O. (2015) Breeding and Domesticating Crops Adapted to Drought and Salinity: A New Paradigm for Increasing Food Production. Frontiers in Plant Science, 6, 978.

https://doi.org/10.3389/fpls.2015.00978

[8] Farooq, M., Wahid, A., Kobayashi, N., Fujita, D. and Basra, S.M.A. (2009) Plant Drought Stress: Effects, Mechanisms and Management. Agronomy for Sustainable Development, 29, 135-212. https://doi.org/10.1051/agro:2008021

[9] Waterworth, W.M., Bray, C.M. and West, C.E. (2015) The Importance of Safeguarding Genome Integrity in Germination and Seed Longevity. Journal of Experimental Botany, 66, 3549-3558. https://doi.org/10.1093/jxb/erv080

[10] Larcher, W. (2006) Ecofisiologia Vegetal. RiMa, São Carlos.

[11] Li, X. and Liu, F. (2016) Drought Stress Memory and Drought Stress Tolerance in Plants: Biochemical and Molecular Basis. In: Hossain, M.A., Wani, S.H., Bhattacharjee, S., Burritt, D.J. and Tran, L.-S.P., Eds., Drought Stress Tolerance in Plants. Physiology and Biochemistry, Springer Nature, Switzerland, 17-44. https://doi.org/10.1007/978-3-319-28899-4_2

[12] Singh, H., Jassal, R.K., Kang, J.S., Sandhu, S.S., Kang, H. and Grewal, K. (2015) Seed Priming Techniques in Field Crops-A Review. Agricultural Reviews, 36, 251-264. https://doi.org/10.18805/ag.v36i4.6662

[13] Conrath, U. (2011) Molecular Aspects of Defence Priming. Trends in Plant Science, 16, 524-531. https://doi.org/10.1016/j.tplants.2011.06.004

[14] Nawaz, J., Hussain, M., Jabbar, A., Nadeem, G.A., Sajid, M., Subtain, M. and Shabbir, I. (2013) Seed Priming A Technique. International Journal of Agriculture and Crop Sciences, 6, 1373-1381.

[15] Sheykhbaglou, R., Rahimzadeh, S., Ansari, O. and Sedghi, M. (2014) The Effect of Salicylic Acid and Gibberellin on Seed Reserve Utilization, Germination and Enzyme Activity of Sorghum (Sorghum bicolor L.) Seeds under Drought Stress. Journalof Stress Physiology \& Biochemistry, 10, 5-13.

[16] Villela, F.A., Doni Filho, L. and Sequeira, E.L. (1991) Tabela de potencial osmótico em função da concentração de polietileno glicol 6.000 e da temperatura. Pesquisa Agropecuária Brasileira, 26, 1957-1968. 
[17] Rhoades, J.D., Kandiah, A. and Mashal, A.M. (1992) The Use of Salt Water for Crop Production. FAO, Rome.

[18] Brasil. Ministério da Agricultura, Pecuária e Abastecimento (2009) Regras para Análise de Sementes. Mapa/ACS, Brasília.

[19] Maguire, J.D. (1962) Speed of Germination Aid in Selection and Evaluation for Seedling Emergence and Vigor. Crop Science, 2, 176-177. https://doi.org/10.2135/cropsci1962.0011183X000200020033x

[20] Zhang, F., Yu, J., Johnston, C.R., Wang, Y., Zhu, K., Lu, F., Zhang, Z. and Zou, J. (2015) Seed Priming with Polyethylene Glycol Induces Physiological Changes in Sorghum (Sorghum bicolor L. Moench) Seedlings under Suboptimal Soil Moisture Environments. PLOS ONE, 10, e0140620. https://doi.org/10.1371/journal.pone.0140620

[21] Kalpana, A.H., Khan, A.K., Singh, K.N., Maurya, S.J.P., Mubeen, R.K., Yadava, U., Singh, A.K. and Gautam, R. (2015) Effect of Different Seed Priming Treatments on Germination, Growth, Biochemical Changes and Yield of Wheat Varieties under Sodic Soil. International Journal of Science and Research, 4, 306-310.

[22] Taiz, L. and Zeiger, E. (2013) Fisiologia Vegetal. 5th Edition, Artmed, Porto Alegre.

[23] Younesi, O. and Moradi, A. (2015) Effect of Different Priming Methods on Germination and Seedling Establishment of Two Medicinal Plants under Salt Stress. Cercetări Agronomiceîn Moldova, 163, 43-51.

[24] Maasoumeh, A.A. and Mohammad, S. (2014) The Effect of Osmo and Hormone Priming on Germination and Seed Reserve Utilization of Millet Seeds under Drought Stress. Journal of Stress Physiology \& Biochemistry, 10, 214-221.

[25] Javid, M.G., Sorooshzadeh, A., Moradi, F., Sanavy, S.A.M.M. and IrajAllahdadi, I. (2011) Review Article the Role of Phytohormones in Alleviating Salt Stress in Crop Plants. Australian Journal of Crop Science, 5, 726-734.

[26] Tian, Y., Guan, B., Zhou, D., Yu, J., Li, G. and Lou, Y. (2014) Responses of Seed Germination, Seedling Growth, and Seed Yield Traits to Seed Pretreatment in Maize (Zea mays L.). The Scientific World Journal, 2014, Article ID: 834630.

[27] Comas, L.H., Becker, S.R., Cruz, V.M.V., Byrne, P.F. and Dierig, D.A. (2013) Root Traits Contributing to Plant Productivity under Drought. Frontiers in Plant Science, 4, 442. https://doi.org/10.3389/fpls.2013.00442

[28] Bahrani, A. and Pourreza, J. (2012) Gibberlic Acid and Salicylic Acid Effects on Seed Germination and Seedlings Growth of Wheat (Triticum aestivum L.) under Salt Stress Condition. World Applied Sciences Journal, 18, 633-641.

[29] Nasibi, F., Kalantari, K.M., Zanganeh, R., Mohammadinejad, G. and Oloumi, H. (2016) Seed Priming with Cysteine Modulates the Growth and Metabolic Activity of Wheat Plants under Salinity and Osmotic Stresses at Early Stages of Growth. Indian Journal of Plant Physiology, 21, 279-286. https://doi.org/10.1007/s40502-016-0233-4

[30] Anosheh, H.P., Sadeghi, H. and Emam, Y. (2012) Chemical Priming with Urea and KNO3 Enhances Maize Hybrids (Zea mays L.) Seed Viability under Abiotic Stress. Journal of Crop Science and Biotechnology, 14, 289-295. https://doi.org/10.1007/s12892-011-0039-x

[31] Daffalla, H.M., Hassan, M.M., Osman, M.G., Eltayeb, A.H.E., Dagash, Y.I. and Gani, M.E.A. (2014) Effect of Seed Priming on Early Development of Sorghum (Sorghum bicolor L. Moench) and Strigahermonthica (Del.) Benth. International Scholarly Research Notices, 2014, Article ID: 134931. 